\title{
KHẢO SÁT THỰC TRẠNG GIÁO DỤC SỨC KHỎE CHO NGƯờI BÊNH TĂNG HUYẾT ÁP TẠI BỆNH VIỆN TRƯỜNG ĐẠI HỌC Y KHOA VINH NĂM 2020
}

\section{TÓM TẮT}

Mục tiêu: 1. Mô tả thực trạng giáo dục sức khỏe cho NB tăng huyết áp tại bệnh viện Trường đại học Y khoa Vinh năm 2020. 2. Khảo sát hiệu quả giáo dục sức khỏe cho NB tăng huyết áp hiện nay tai bệnh viện Trường đại học Y khoa Vinh năm 2020. Đối tượng và phương pháp nghiên cứu: Nghiên cứu mô tá cắt ngang 50 NB được chẩn đoán THA đến khám và điều trị tại Bệnh viện Trường Đại học Y khoa Vinh từ tháng 08/2020 đến tháng 10/2020. Kết quả: 100\% người bệnh tăng huyết áp được nhân viên y tế giáo dục sức khỏe. Đa số người bệnh có kiến thức về bệnh THA như biểu hiện, trị số huyết áp, thời điểm đo huyết áp bênh THA. 72\% người bênh có kiến thức về nguyên tắc điều trị THA là điều trị lâu dài; chỉ có $4 \%$ người bệnh không biết nguyên tắc điều trị của bênh THA. Kết luận: Giáo dục sức khoẻ cho người bệnh THA tại bệnh viện Trường đại học Y khoa Vinh năm 2020 được thực hiện có hiệu quả tuy nhiên bệnh viện cần có chương trình GDSK cho người bênh THA tiến hành đánh giá thường xuyên hiệu quả hoạt động truyền thông, giáo dục sức khỏe cho người bệnh.

Tư khóa: tăng huyết áp, NB, giáo dục sức khỏe.

\section{SUMMARY}

\section{SURVEY ON THE SITUATION OF HEALTH EDUCATION FOR HYPERTENSIVE PATIENT AT THE HOSPITAL OF VINH MEDICAL UNIVERSITY IN 2020}

Objectives: 1 . Describe the current situation of health education for hypertensive patients at Vinh Medical University Hospital in 2020. 2. Survey the effectiveness of health education for hypertensive patients at Vinh University Medicine Hospital in 2020. Subjects and methods: A cross-sectional descriptive study of 50 patients diagnosed with hypertension who came for examination and treatment at Vinh Medical University Hospital from August 2020 until October 2020. Results: 100\% of hypertensive patients received health education by medical staffs. Most patients have knowledge about hypertension such as symptoms, blood pressure values, and time to measure blood pressure. $72 \%$ of patients have knowledge about the principles of hypertension treatment as long-term treatment; Only $4 \%$ of patients do not know the principles of treatment of hypertension. Conclusion: Health education for hypertensive patients at Vinh Medicine University Hospital in 2020 is effective, but the

${ }^{1}$ Trường Đại hoc Y khoa Vinh

Chịu trách nhiệm chính: Đinh Thị Hằng Nga

Email: ngadinh.dhykvinh@gmail.com

Ngày nhận bài: 9.8.2021

Ngày phản biên khoa học: 4.10 .2021

Ngày duyệt bài: 15.10 .2021

\section{Đinh Thị Hằng Nga ${ }^{1}$, Hồ Thị Hải Lế}

hospital needs a health education program for hypertensive patients to regularly evaluate the effectiveness of communication and health education activities for patients.

Keywords: hypertension, patients, health education.

\section{I. ĐĂT VẤN ĐỀ}

THA là bệnh lý xuất hiện âm thầm nhưng để lại biến chứng nghiêm trọng cho NB khi không được kiểm soát tốt. Trong những năm gần đây, tỷ lệ tử vong do các biến chứng của bệnh THA ngày một tăng ở các nước đang phát triển, trong đó có Việt Nam. Theo Hội tim mạch Việt Nam 2015 cho thấy tại Việt Nam có đến $47.3 \%$ người trên 25 tuổi bị mắc HA [1]. Bệnh để lại di chứng rất nặng và có thể tử vong do những biến chứng của bệnh hoặc do tai biến điều trị. GDSK là một công tác khó làm và khó đánh giá kết quả, nhưng nếu làm tốt sẽ mang lại hiệu quả cao nhất với chi phí ít nhất, nhất là ở tuyến y tế cơ sở. Theo tổ chức y tế thế giới, $80 \%$ bệnh tim mạch, đái tháo đường có thể phòng được thông qua thực hiện lối sống lành mạnh loại bỏ các yếu tố liên quan hành vi [3].

Hiện nay, tại bệnh viện trường đại học Y khoa Vinh lượng người có bệnh THA đến khám và điều trị ngày càng tăng lên. Số lượng NB trung bình trong một tháng cần nằm và điều trị tại bệnh viện có xu hướng gia tăng. Thực trạng triển khai công tác GDSK cho NB THA tại bệnh viện trường đại học $Y$ khoa Vinh đã triển khai như thế nào? Hiệu quả của chương trình GDSK NB THA tại bệnh viện trường đại học y khoa Vinh như thế nào? Mục tiêu nghiên cứu

1. Mô tả thực trang giáo dục sức khỏe cho NB tăng huyêt áp tại bệnh viện Trường đại học Y khoa Vinh năm 2020

2. Khảo sát hiệu quả giáo dục sức khỏe cho NB tăng huyết áp hiện nay tại bệnh viện Trường đại hoc Y khoa Vinh năm 2020

\section{II. ĐỐI TƯỢNG VÀ PHƯƠNG PHÁP NGHIÊN CỨU}

1. Đối tượng nghiên cứu: NB THA đến khám và điều trị tại Bệnh viện Trường Đại học $Y$ khoa Vinh.

2. Thời gian và địa điểm nghiên cứu: Từ tháng 08/2020 đến tháng 10/2020, tại Bệnh viện Trường Đại học $Y$ khoa Vinh

3. Phương pháp nghiên cứu: Nghiên cứu mô tả cắt ngang 
4. Cỡ mẫu: Cõ̃ mẫu là 50 với phương pháp chọn mẫu thuận tiện.

5. Phương pháp phân tích số liêu: Các số liệu điều tra được thu thập và xử lý qua qua Exel

\section{KẾT QUẢ NGHIÊN CỨU}

1. Thực trạng GDSK cho NB THA tại bệnh viện Trường đại học $Y$ khoa Vinh năm 2020

Bảng 3.2. Thức trang GDSK của NB THA tại BV trường ĐH Y khoa Vinh $(n=50)$

\begin{tabular}{|c|c|c|c|}
\hline \multicolumn{2}{|c|}{ Thông tin chung } & \multirow{2}{*}{$\begin{array}{c}\text { Tân suất } \\
\text { (n) }\end{array}$} & \multirow{2}{*}{\begin{tabular}{|c|}
$\begin{array}{c}\text { Tỷ lề } \\
\text { \% }\end{array}$ \\
100,0
\end{tabular}} \\
\hline $\begin{array}{c}\text { Oược nhâr } \\
\text { viển y tế } \\
\text { GDSK }\end{array}$ & Có & & \\
\hline \multirow{2}{*}{$\begin{array}{c}\text { Người thự } \\
\text { hiện tư } \\
\text { vấn GDSK }\end{array}$} & Điêu dưỡng & 37 & 74,0 \\
\hline & Bác sĩ & 44 & 88,0 \\
\hline \multirow{2}{*}{$\begin{array}{l}\text { Hình thức } \\
\text { GDSK }\end{array}$} & $\begin{array}{l}\text { Tổ chức nói } \\
\text { chuyện GDSK }\end{array}$ & 16 & 32,0 \\
\hline & Tư vấn cá nhân & 40 & 80,0 \\
\hline \multirow{3}{*}{$\begin{array}{l}\text { Tài liệu } \\
\text { dùng để tı } \\
\text { vấn GDSK }\end{array}$} & Tờ rơi & 10 & 20,0 \\
\hline & Tài liệu phát tay & 36 & 72,0 \\
\hline & Tranh ảnh & 4 & 8,0 \\
\hline \multirow{3}{*}{$\begin{array}{c}\text { Thời điểm } \\
\text { NB THA } \\
\text { được } \\
\text { GDSK }\end{array}$} & Lúc vào viện & 23 & 46,0 \\
\hline & $\begin{array}{c}\text { Trong quá trình } \\
\text { điêuu trị }\end{array}$ & 29 & 58,0 \\
\hline & Trước lúc ra viện & 26 & 52,0 \\
\hline \multirow{9}{*}{$\begin{array}{l}\text { Nội dung } \\
\text { GDSK }\end{array}$} & Nguyên nhân & 27 & 54,0 \\
\hline & Triệu chứng THA & 34 & 68,0 \\
\hline & Điều trị & 33 & 66,0 \\
\hline & Biến chứng & 32 & 64,0 \\
\hline & $\begin{array}{l}\text { Cách dự phòng } \\
\text { biến chứng }\end{array}$ & 43 & 86,0 \\
\hline & Chế độ dinh dưỡng & 42 & 84,0 \\
\hline & Tuân thủ dùng thuốc & 41 & 82,0 \\
\hline & Tái khám & 46 & 92,0 \\
\hline & Vận động & 33 & 66,0 \\
\hline
\end{tabular}

Tỉ lê NB THA được nhân viên y tế GDSK cao $(100 \%)$; người thực hiện GDSK cho NB là bác sĩ chiếm tỉ lệ cao hơn $(88,0 \%)$; hình thức GDSK qua tư vấn cá nhân chiếm tỉ lệ cao $(80,0 \%)$, hình thức tổ chức nói chuyện GDSK còn thấp $(32,0 \%)$; tài liệu phát tay được sử dụng để tư vấn GDSK chiếm tỉ lệ cao nhất $(72,0)$

NB được GDSK tương đối đồng đều ở cả 3 thời điểm, hướng dẫn NB tái khám $(92,0 \%)$, cách dự phòng biến chứng $(86,0 \%)$. Thấp nhất là nguyên nhân $(54,0 \%)$, hướng dẫn vận động $(66,0 \%)$

2. Đánh giá hiệu quả hương trình GDSK cho NB THA tại bệnh viện Trường đại học $Y$ khoa Vinh hiện nay

Bảng 3.3. Kiến thức của NB về bệnh THA

\begin{tabular}{|c|c|c|c|}
\hline \\
\hline \multicolumn{2}{|c|}{ Thông tin chung } & $\mid \begin{array}{c}\text { Tấn } \\
\text { suất(n) }\end{array}$ & $\begin{array}{l}\text { Tỳ lệ } \\
\% \%\end{array}$ \\
\hline \multirow{6}{*}{$\begin{array}{c}\text { Biểu } \\
\text { hiện bệnh } \\
\text { THA }\end{array}$} & Nhức đầu sau gáy & 23 & 46,0 \\
\hline & Chóng mặt, hoa mắt & 42 & 84,0 \\
\hline & Buồn nôn & 24 & 48,0 \\
\hline & Nóng bừng mặt & 28 & 56,0 \\
\hline & Mệt mỏi & 38 & 76,0 \\
\hline & Không biết & 0 & 0 \\
\hline \multirow{3}{*}{$\begin{array}{l}\text { Chỉ số HA } \\
\text { để đánh } \\
\text { giá trình } \\
\text { trạng THA }\end{array}$} & $\begin{array}{c}\text { HA tối đa } \geq \\
140 \mathrm{mmHg}\end{array}$ & 31 & 62,0 \\
\hline & $\begin{array}{c}\text { HA tối thiểu } \geq \\
90 \mathrm{mmHg}\end{array}$ & 10 & 20,0 \\
\hline & $\begin{array}{l}\text { HATÐ } \geq 140 \mathrm{mmHg} \\
\text { và } \mathrm{HATT} \geq 90 \mathrm{mmHg}\end{array}$ & 27 & 54,0 \\
\hline \multirow{3}{*}{$\begin{array}{c}\text { Kiến thức } \\
\text { về thời } \\
\text { điểm đo } \\
\text { HA }\end{array}$} & Hằng ngày & 46 & 92,0 \\
\hline & Thường xuyên & 12 & 24,0 \\
\hline & $\begin{array}{c}\text { Khi mệt mỏi, đau đầu } \\
\text { chóng mặt }\end{array}$ & 24 & 48,0 \\
\hline \multirow{4}{*}{$\begin{array}{c}\text { Kiến thức } \\
\text { về chế độ } \\
\text { dinh } \\
\text { dưỡng cho } \\
\text { NB THA }\end{array}$} & Đủ năng lượng & 28 & 56,0 \\
\hline & $\begin{array}{c}\text { Tăng cường rau xanh } \\
\text { hoa quả }\end{array}$ & 34 & 68,0 \\
\hline & $\begin{array}{l}\text { Hạn chế: chất béo, } \\
\text { muối, rượu bia, thuốc } \\
\text { lá, chất kích thích }\end{array}$ & 50 & 100 \\
\hline & Đủ nước & 20 & 40,0 \\
\hline
\end{tabular}

NB có kiến thức về biểu hiên bênh THA cao nhất là hoa mắt, chóng mặt $(84,0 \%)$, NB có kiến thức về trị số $\mathrm{HA}$ tăng, cao nhất là $\mathrm{HA}$ tối đa $\geq$ $140 \mathrm{mmHg}(62,0 \%)$, HA tối thiểu $\geq 90 \mathrm{mmHg}$ $(20,0 \%)$, NB có kiến thức về thời điểm đo HA tai nhà cao nhất là hằng ngày $(92,0)$; $\mathrm{NB}$ có kiến thức về chế độ dinh dưỡng cho người THA cao nhất là hạn chế: chất béo, muối, rượu bia, thuốc lá, chất kích thích (100\%)

Bảng 3.4: Kiến thức về yêu tố nguy cơ của bệnh THA $(n=50)$

\begin{tabular}{|c|c|c|}
\hline Yếu tố nguy cơ & $\begin{array}{c}\text { Tân suất } \\
\text { (n) }\end{array}$ & $\begin{array}{c}\text { Tỷ lệ } \\
\text { \% }\end{array}$ \\
\hline$>45$ tuổi & 33 & 66,0 \\
\hline Thừa cân & 36 & 72,0 \\
\hline Sử dụng rượu bia, thuốc lá & 33 & 66,0 \\
\hline Án nhiều muối, ít rau quả. & 31 & 62,0 \\
\hline İt hoạt động thế lực. & 31 & 62,0 \\
\hline Căng thằng tâm lý. & 34 & 68,0 \\
\hline Mắc các bệnh mạn tính & 29 & 58,0 \\
\hline Tiền sử bệnh trong gia đình & 28 & 56,0 \\
\hline Không biết & 2 & 4,0 \\
\hline
\end{tabular}

NB có kiến thức về yếu tố nguy cơ của bênh THA cao nhất là thừa cân $(72,0 \%)$, thấp nhất là NB không biết về yếu tố nguy cơ THA $(4,0 \%)$

Bảng 3.5: Kiến thức về biến chứng bệnh THA $(n=50)$ 


\begin{tabular}{|c|c|c|}
\hline Biến chứng & $\begin{array}{c}\text { Tân } \\
\text { suất }(\mathbf{n})\end{array}$ & Tỷ lệ \%o \\
\hline Tai biến mạch máu não & 33 & 66,0 \\
\hline Nhồi máu cơ tim & 34 & 68,0 \\
\hline Suy thận & 17 & 34,0 \\
\hline Biến chứng về mắt & 15 & 30,0 \\
\hline Không biết & 2 & 4,0 \\
\hline
\end{tabular}

NB có kiến thức về biền chứng của bênh THA cao nhất là nhồi máu cơ tim(68\%) tai biến mạch máu não $(66,0 \%)$, thấp nhất là NB không biết về biến chứng của bênh THA $(4,0 \%)$

Bảng 3.6: Kiến thức về điều trị THA $(n=50)$

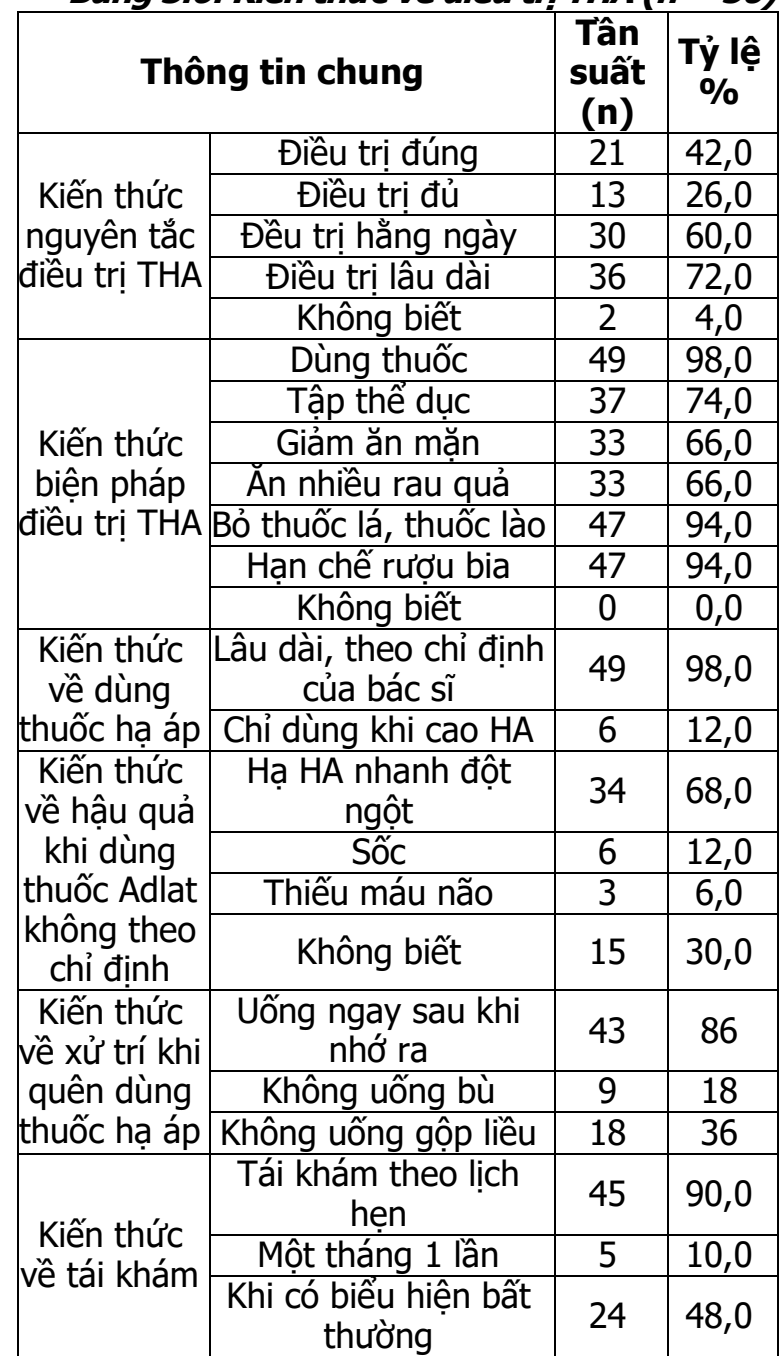

NB có kiến thức về nguyên tắc điều trị THA cao nhất là điều trị lâu dài $(72,0 \%)$, thấp nhất là không biết nguyên tắc điều trị của bệnh THA $(4,0 \%) ; N B$ có kiến thức về biện pháp điều trị THA cao nhất là dùng thuốc $(98,0 \%)$, bỏ thuốc lá, thuốc lào, hạn chế rượu bia $(94,0 \%)$; NB có kiến thức về dùng thuốc hạ áp cho người THA cao nhất là lâu dài, theo chỉ định của bác sĩ
$(98,0 \%)$, NB không có kiến thức về hậu quả khi sử dụng thuốc Adlat không theo chỉ đinh dẫn đến hạ HA nhanh đột ngột cao nhất $(68,0 \%)$, thấp nhất là hậu quả thiếu máu não $(6,0 \%)$, sốc $(12,0 \%)$; NB có kiến thức về xử trí khi quên dùng thuốc hạ áp cao nhất là uống ngay sau khi nhớ ra $(86 \%)$, NB có kiến thức tái khám cao nhất là tái khám theo lịch hẹn $(90 \%)$

\section{BÀN LUẬN}

1. Thực trang GDSK cho NB THA tại bệnh viện Trưởng đại học $Y$ khoa Vinh năm 2020. Kết quả thu được cho thấy tỉ lệ NB THA điều trị tại bệnh viện Trường đại học Y khoa Vinh năm 2020 được nhân viên y tế GDSK cao $(100 \%)$, tỉ lệ bác sĩ tham gia GDSK cho NB (88\%) chiếm tỉ lê cao hơn điều dưỡng $(74 \%)$ và hình thức GDSK chủ yếu là tư vấn cá nhân $(80 \%)$. Thực trạng cho thấy các nhân viên y tế luôn lồng ghép việc GDSK cho NB THA trong quá trình chăm sóc và điêu trị tại bệnh viện tuy nhiên vai trò của người điêuu dưỡng trong công tác GDSK cho NB cần được chú trọng hơn. So với nghiên cứu của Pham Thi Trang (2013) tỉ lê NB THA tại bệnh viện Tim Hà Nội được nhân viên y tế tư vấn GDSK $(64,9 \%)$, có nhưng chưa đầy đủ $(35,1 \%)$. Nghiên cứu của Nguyễn Thái Quỳnh Chi 2018 Kết quả cho thây NB đánh giá điêu dưỡng có thực hiện 8 hoạt động trong nhiệm vụ tư vấn, hướng dẫn GDSK với tỷ lệ từ $67,5-$ $90 \%$; tuy nhiên, qua quan sát thực hành, chỉ có $62,5 \%$ điều dướng được đánh giá "đat" khi thực hiên nhiêm vụ. Yếu tố ảnh hưởng đển việc thực hiện nhiệm vụ tư vấn, hướng dẫn GDSK cho NB của điều dưỡng bao gồm: số lượng NB phải chăm sóc; hoạt động đào tạo, bồi dưỡng kiến thức; và hoạt động kiểm tra, giám sát hỗ trợ.

Về thời điểm GSSK cho NB THA ở cả 3 thời điểm tương đối đồng đều tuy nhiên chưa đạt tî lệ cao. Cụ thể thời điểm GDSK cho NB THA lúc vào viện $(46 \%)$, trong quá trình điều trị $(58 \%)$, trước lúc ra viện (52\%). Nội dung GDSK cho NB THA đạt tỉ lệ cao nhất là hướng dần NB tái khám (92\%), thấp nhất là nguyên nhân (54\%). Thực tế cho thấy hướng dẫn NB tái khám đạt tî lệ cao do NB THA trước khi ra viện có đơn thuốc kê về nhà, nhân viên y tế sẽ dặn tái khám sau khi dùng hết đơn và hầu hết các trường hợp THA đều không rõ nguyên nhân và được gọi là THA vô căn và cao $\mathrm{HA}$ thứ phát là hệ quả của một số bệnh lý như bệnh thận, bệnh tuyến giáp, u tuyến thượng thận hay tác dụng gây ra...

2. Hiệu quả chương trình GDSK cho người bệ̉nh THA tại bệnh viện Trường đại 
học Y khoa Vinh năm 2020. Trong tổng số 50 NB THA được nghiên cứu, NB có kiến thức về trị số $\mathrm{HA}$ tăng, cao nhất là $\mathrm{HA}$ tối đa $\geq 140 \mathrm{mmHg}$ (62\%), HA tối thiểu $\geq 90 \mathrm{mmHg}(20 \%)$, không có NB không biết (0\%); NB có kiến thức về thời điểm đo $\mathrm{HA}$ tại nhà cao nhất là hằng ngày (92\%), không có NB không biết (0\%). So với nghiên cứu của Pham Thị Trang (2013) tỷ lệ NB hiểu đúng chỉ số HA cao chiếm tỷ lệ $42,1 \%$, tỷ lệ người hiểu sai về chỉ số $\mathrm{HA}$ cao hoặc không biết chiếm $57.9 \%$; Tỷ lệ người thường xuyên đo và ghi lại HA của mình chiếm tỷ lê $32.9 \%$, tỷ lệ NB không theo HA thường xuyên là $67.1 \%$. Việc NB thường xuyên đo và ghi lại $\mathrm{HA}$ của mình rât quan trọng cho bác sĩ trong việc điều trị và kiểm soát HA. Theo nghiên cứu của Trương Thị Thùy Dương (2016) số đối tượng nghiên cứu biết số đo HA của bản thân chiểm tỷ lệ rất thấp (chung hai xã là $14,1 \%$, xã đối chứng là $15,1 \%$ và xã can thiệp là 13,2\%). Thực tế cho thấy người dân ở cộng đồng có THA nhưng họ không biết vì vậy họ không phòng chống, không điều trị nên rất dễ xảy ra tai biến.

Kết quả nghiên cứu cho thấy NB có kiến thức về yếu tố nguy cơ của bệnh THA cao nhất là thừa cân $(72 \%)$, sử dụng rượu bia thuốc lá $(66 \%)$, ăn nhiều muối $(6,2 \%)$, thấp nhất là NB không biết về yễu tố nguy cơ THA (4\%). Tỷ lệ biết đúng về các yếu tố nguy cơ của bệnh THA ở NB trong nghiên cứu này cao hơn kết quả nghiên cứu năm 2002 của Phạm Gia Khải và cộng sự điều tra 5.012 người từ 25 tuổi trở lên tại 4 tỉnh miền Bắc Việt Nam (Nghê An, Hà nội, Thái Bình và Thái Nguyên), tỷ lệ biết đúng của nghiên cứu đó chỉ là $23 \%$. Sở dĩ có sự chênh lệch đó là do $100 \%$ NB đến khám được nhân viên y tế tư vấn. Trong các yếu tố nguy cơ trên thì thừa cân, thói quen ăn mặn, uống nhiều rượu, bia được NB biết đến nhiều bởi lẽ NB điều trị tại bệnh viện đã được tư vấn, kê đơn và dặn dò trong mỗi lần đến khám bệnh hàng tháng.

Nghiên cứu của chúng tôi cho thấy NB có kiến thức về biến chứng của bệnh THA cao nhất là nhồi máu cơ tim $(68 \%)$ tai biến mạch máu não (66\%), suy thận (34\%), mắt (30\%) thấp nhất là NB không biết về biến chứng của bệnh THA (4\%). Tỷ lệ NB biết đến các tai biến của THA gây ra tương đương với tỷ lệ hiểu biết về các yếu tố nguy cơ. Trong phần tư vấn của nhân viên y tế thường trọng vấn về các yếu tố nguy cơ nhiều hơn để mong muốn NB thay đổi hành vi lối sống, phối hợp với việc dùng thuốc để việc điều trị, kiểm soát HA tốt. So với nghiên cứu của Pham Thị Trang cho thấy tỷ lệ NB biết về các tai biến của THA khi không điều trị hoặc điều trị chưa đạt hiệu quả là thấp hơn; nguy cơ tai biến mạch máu não chiếm $63.3 \%$, nhồi máu cơ tim $57.8 \%$, suy tim $72,0 \%$, giảm thị lực $55.9 \%$, tai biến suy.

Về nguyên tắc điều trị THA $72 \%$ NB có kiến thức về nguyên tắc điều trị THA là điều trị lâu dài, 4\% NB không biết nguyên tắc điều trị của bệnh THA; $98 \%$ NB có kiến thức về biện pháp điêu trị THA cao nhất là dùng thuốc, $94 \%$ bỏ thuốc lá, thuốc lào, hạn chế rượu bia; không có NB không biết biện pháp điều trị của bệnh THA $(0 \%)$. Theo nghiên cứu của Phạm Thùy Trang tỷ lệ NB hiểu biết về các biện pháp không dùng thuốc làm giảm HA: Ngừng hút thuốc lá $64,9 \%$, ngừng hút thuốc lào $64,9 \%$, bỏ thói quên ăn mặn $98,2 \%$, giảm cân $71,8 \%$, không dùng rượu bia, chất kích thích 85,9\%, tập thể dục thường xuyên 95,5\%, tránh căng thẳng trong cuộc sống $100 \%$.

Kết quả nghiên cứa của chúng tôi cho thây NB có kiến thức về chế độ dinh dưỡng cho người THA cao nhất là hạn chể: chất béo, muối, rượu bia, thuốc lá, chất kích thích (100\%), không có NB không biết (0\%). Nghiên cứu của Nguyễn Thị Thùy Dương 2016 Tỷ lệ đối tượng nghiên cứu biết THA có thể dự phòng được chung hai xã thuộc huyện Lục Bình - Hà Nam là 66,8\%, xã đối chứng $76,2 \%$ và $59,0 \%$ ở xã can thiệp, trong đó, số người biết biện pháp ăn giảm chất béo chiếm tỷ lệ cao nhất (chung hai xã là 19,7\%, xã đối chứng là $22,9 \%$, xã can thiệp là 18,3\%), thấp nhất là biện pháp tránh căng thẳng thần kinh (chung hai xã là 2,7\%, xã đối chứng là 4,8\%, xã can thiệp là 1,0\%).

Về kiến thức xử trí khi quên dùng thuốc hạ áp NB có kiến thức về xử trí khi quên dùng thuốc hạ áp cao nhất là uống ngay sau khi nhớ ra $(86 \%)$,

Về kiến thức tái khám: có $90 \%$ NB THA có kiến thức tái khám theo lịch hẹn và không có NB nào không biết. Theo nghiên cứu của Phạ Thế Xuyên tỉ lệ tham gia điều trị THA của các ĐTNC bị THA ở hai xã can thiệp và đối chứng là khá cao, lân lượt là $90 \%$ và $92,8 \%$. Tuy nhiên, tỷ lệ tuân thủ điều trị lại đạt khá thấp, chỉ đạt lần lượt là $26,4 \%$ và $23,4 \%$. Không có sự khác nhau về tham gia và tuân thủ điều trị THA ở hai xã. So với nghiên cứu của Phạm Thị Trang tất cả NB đều tuyệt đối tuân thủ y lệnh bác sĩ, không tự thay đổi thuốc mà không hỏi y kiến của bác sĩ, tái khám theo hẹn của bác sĩ, biết khám lại ngay khi có dấu hiệu bất thường. Về kiến thức dùng thuốc, NB uống thuốc đều đặn theo đơn của bác sĩ. Không có trường hợp nào trả lời chỉ uống 
thuốc khi huyết cao hay chỉ uống khi có dấu hiệu của THA (đau đâu, chóng mặt, hoa mắt...).

\section{KẾT LUÂ̂N}

1. Thực trạng giáo dục sức khỏe cho người bệnh tăng huyết áp tại bệnh viện Trường đại học Y khoa Vinh năm 2020

- 100\% người bệnh tăng huyết áp được nhân viên y tế giáo dục sức khỏe với tư vấn cá nhân $(80 \%)$ và tài liệu phát tay $(72 \%)$.

- 70,4\% người bệnh được tư vấn, giáo dục sức khỏe phù hợp với bệnh khi vào viện, trong quá trình điêuu trị và lúc ra viện

- 81,5\% nhân viên đánh giá bệnh viện không tiến hành đánh giá (hoặc nghiên cứu) hiệu quả hoạt động truyên thông, giáo dục sức khỏe cho người bệnh.

2. Hiệu quả chương trình giáo dục sức khỏe cho người bệnh tăng huyết áp tại bệnh viện Trường đại học $Y$ khoa Vinh

- Đa số người bệnh có kiến thức về bệnh THA như biểu hiện, trị số huyết áp, thời điểm đo huyết áp bệnh THA

- 72\% người bệnh có kiến thức về nguyên tắc điều trị THA là điều trị lâu dài,

- Chỉ có 4\% người bệnh không biết nguyên tắc điều trị của bệnh THA

- 90\% người bệnh THA có kiến thức tái khám theo lịch hẹn

TÀI LIẸU THAM KHẢO

1. Hội tim mạch Việt Nam (2018), "Khuyến cáo về chẩn đoán điều trị \& dư phòng THA". Trang web http://vnha.org.vn/data/Khuyen-Cao-THA-2018, truy câp ngày 20/3/2020

2. Cục y tế dự phòng, Bộ Y tế (2015), "THA, kẻ giết người thiâm lă̆ng"

3. Tan Van Bui, Christopher Leigh Blizzard., Khue Ngoc Luong, Ngoc Le Van Truong, Bao Quoc Tran, Petr Otahal, Mark R.Nelson Seana Gall. and and at el (2016), "National survey of risk factors for noncommunicable disease in Vietnam: prevalence estimates and an assessment of their validity", BMC Public Health, Volume 16, pp.489.

4. Nguyễn Thái Quỳnh Chi (2018) tạp chí khoa học tập 3 số 2-2019. Đánh giá việc thực hiên nhiệm vụ tư vấn, hướng dẫn GDSK cho bênh nhẩn Khoa Nội Tim mạch-Lão học, Bệnh viện đa khoa tỉnh Khánh Hòa năm 2018

5. Trương Thị Thùy Dương (2016) Hiêuu quả của mô hình truyền thông giáo dục dinh dưỡng nhằm cải thiên môt số yếu tố nguy cớ THA tai công đồng

6. Trân Thị Hằng Nga (2018), "đánh giá hoạt động GDSK của người điều dưỡng bệnh viện đa khoa tỉnh Quảng Trị và một số yếu tố liên quan, năm 2018", Khoa học điều dưỡng tập 1 (số 3 2018)

7. Carlo Marra., Karissa Johnston. and Valerie Santschi (2017), "Cost-effectiveness of pharmacist care for managing hypertension in Canada", Canada Pharmacists Jounal, Volum 150(3), pp.184-197.

\section{KẾT QUẢ PHẪU THUÂT ĐÎ̀̂U TRI BONG VÕNG MẠC CO KÉO DO ĐÁI THÁO ĐƯờNG CÓ SỬ DỤNG PFCL}

\section{TÓM TẮT.}

Mục tiêu: đánh giá kết quả phẫu thuật điều trị bong võng mạc co kéo do đái tháo đường (ĐTĐ) có sử dụng dung dịch Perfluorocarbon (PFCL). Đối tượng và phương pháp nghiên cứu: nghiên cứu can thiệp lâm sàng không đối chứngtrên 21 bệnh nhân (21 mắt) bị bong võng mạc co kéo do ĐTĐ. Kết quả: tại thời điểm 3 tháng sau phẫu thuật, tỷ lệ võng mạc áp là95,2\% (20/21 ca) thị lực cải thiện so với trước mổ có ý nghĩa thống kê $p<0,001$; các biến chứng gặp sau mổ là: tăng nhãn áp sau 2 ngày $2 \mathrm{ca}$, xuất huyết dịch kính: 2ca, 1 ca xuất hiện màng trước võng mạc. Có sự

\footnotetext{
${ }^{1}$ Trường Đại học Y Hà Nội

²Bênh viện Mắt Trung Ương

Chịu trách nhiệm chính: Vũ Tuấn Anh

Email: vta.oph@gmail.com

Ngày nhận bài: 11.8 .2021

Ngày phản biện khoa học: 5.10.2021

Ngày duyệt bài: 14.10.2021
}

Trần Đăng Quang ${ }^{1}$, Vũ Tuấn Anh ${ }^{2}$

khác biệt về kết quả phục hồi về giải phẫu và chức năng giữa nhóm bong qua hoàng điểm và chưa qua hoàng điểm. Kết luận: phẫu thuật cắt dịch kính điêu trị bong võng mạc co kéo do ĐTĐ có sử dụng PFLC giải phóng mù lòa và khắc phục được biến chứng giai đoạn cuối, nhằm cứu vãn thị lực dù còn thấp cho bệnh nhẩn ĐTĐ biến chứng

Tư khóa: bong võng mạc co kéo do ĐTĐ, cắt dịch kính, PFCL

\section{SUMMARY \\ RESULTS OF VITRECTOMY USING PFCL FOR TREATMENT OF DIABETIC \\ TRACTIONALRETINAL DETACHMENT}

Aims: results of surgery using PFCL for treatment ofdiabetictractional retinal detachment. Methods: interventional cases series. Patients received an Avastinintravitreal injection prior to undergoing vitrectomy to remove hemorrhage, traction and reattach the retina. Results: for 21 cases, results 3 months after surgery: $95,2 \%$ of cases retinal re- 